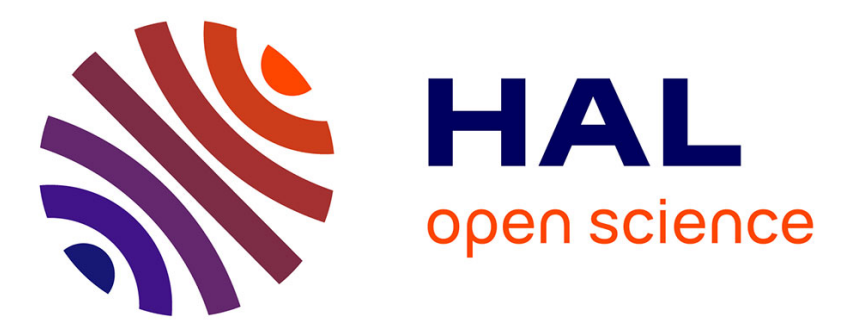

\title{
Enhanced luminescence efficiency in growth interrupted single quantum wells by atomic hydrogen
}

\author{
R. Murray, P. Mookherjee, A. Yoshinaga, P. Dawson
}

\section{To cite this version:}

R. Murray, P. Mookherjee, A. Yoshinaga, P. Dawson. Enhanced luminescence efficiency in growth interrupted single quantum wells by atomic hydrogen. Journal de Physique IV Proceedings, 1993, 03 (C5), pp.C5-441-C5-444. 10.1051/jp4:1993595 . jpa-00251682

\section{HAL Id: jpa-00251682 https://hal.science/jpa-00251682}

Submitted on 1 Jan 1993

HAL is a multi-disciplinary open access archive for the deposit and dissemination of scientific research documents, whether they are published or not. The documents may come from teaching and research institutions in France or abroad, or from public or private research centers.
L'archive ouverte pluridisciplinaire HAL, est destinée au dépôt et à la diffusion de documents scientifiques de niveau recherche, publiés ou non, émanant des établissements d'enseignement et de recherche français ou étrangers, des laboratoires publics ou privés. 


\title{
Enhanced luminescence efficiency in growth interrupted single quantum wells by atomic hydrogen
}

\author{
R. MURRAY, P.B. MOOKHERJEE, A. YOSHINAGA and P. DAWSON* \\ Interdisciplinary Centre for Semiconductor Materials, Imperial College, London, England \\ * Department of Pure and Applied Physics, UMIST, Manchester, U.K.
}

\begin{abstract}
Several groups have demonstrated smoothing of (Al,Ga)As/GaAs quantum well heterointerfaces by growth interrupts (GI). Such quantum wells (QW) usually exhibit multiple narrow line emission spectra where the energy and separation of the peaks is consistent with large lateral islands varying in height by a monolayer. Unfortunately, the integrated emission can be reduced by an order of magnitude as a result of GI. Time decay measurements suggest that GI leads to the incorporation of non-radiative centres. The lifetime and luminescence efficiency can be recovered by annealing the samples for $2 \mathrm{~h}$ in a hydrogen plasma. The $\mathrm{H}$ passivates non-radiative centres but does not degrade the smoothness of the interfaces. These results may have important consequences for the optical and electrical properties of quantum devices.
\end{abstract}

\section{INTRODUCTION}

The observation of multiple narrow emission peaks in $\mathrm{Al}_{\mathrm{x}} \mathrm{Ga}_{1-\mathrm{x}} \mathrm{As} / \mathrm{GaAs}$ quantum wells ( $Q W$ ) which have been subjected to interrupts during growth have been attributed to monolayer (ML) fluctuations at the interfaces. smoothing of the interfaces in quantum structures is desirable from the point of view of increased carrier mobilities (1) and may prove useful for optical devices. We have shown previously that it is necessary to interrupt the growth at both interfaces in order to obtain sharp photoluminescence (PL) and excitation (PLE) spectra (2). Smoothing of the interfaces is also inferred from the recovery of reflection high energy electron diffraction (RHEED) measurements and the recovery curves have been used to estimate suitable GI periods, $t$, which are typically 60 to 120s. However, smoothing of the interfaces by growth interrupts (GI) occurs at the expense of radiative efficiency due to the incorporation of non-radiative centres (3). In this paper we will show that hydrogen passivation of GI structures leads to a recovery of the intensity of the optical emission to the levels exhibited by non-GI samples but the sharp PL features which indicate smooth interfaces are retained. 


\section{EXPERIMENTAL DETAILS}

The AlAs/GaAs single QW structures were grown by molecular beam epitaxy at $630^{\circ} \mathrm{C}$ on continuously rotated GaAs (001) semi-insulating substrates in a vacuum Generators V8OH machine. A growth rate of $1 \mathrm{ML} / \mathrm{s}$ was determined from RHEED measurements. A 6x6ML GaAs/ẢAs superlattice was included in the buffer layer to reduce impurity incorporation (4) and the structure was capped by $500 \AA$ of undoped GaAs. The widths of the barrier and well layers were nominally $22 \mathrm{ML}$ and this was subsequently confirmed by $\mathrm{PL}$ and $\mathrm{X}$-ray diffraction measurements. The optical measurements were made with the samples held in a closed cycle, variable temperature helium cryostat. Excitation was by argon ion or titanium sapphire laser and the luminescence dispersed by a SPEX $0.85 \mathrm{~m}$ double grating monochromator and detected by a cooled GaAss photomultiplier using photon counting. Time decay measurements were made using pulses from a mode-locked argon ion laser and detected by a cooled Hamamatsu SI micro-channel plate detector. The resolution of the system is $90 \mathrm{ps}$. Some samples were also annealed at $280^{\circ} \mathrm{C}$ in an inductively coupled (13.56 MHz) hydrogen plasma for periods up to 6 hours. These conditions have been shown previously to cause passivation of shallow (5) and deep impurities in GaAs (6).

\section{RESULTS}

Figure 1, (spectra are shifted in energy relative to the GI=120s sample for clarity), shows the PLE spectra obtained from a series of nominally identical samples with GI periods of $0,5,10,60$ and 120 s at each interface. For clarity only the el-hnl transitions are shown. For $t=0$ the PLE peak has a width (FWHM) of about $3 \mathrm{mev}$ which is typical of high quality material. As $t$ is increased the emission splits into two or three narrower features. At $t=10 \mathrm{~s}$, two peaks with a FWHM of about $2 \mathrm{meV}$ are observed. The energy and separation of the peaks vary across the sample and do not correspond to integer ML fluctuations in the well width, we attribute this to the presence of roughness on at least one of the interfaces. Increasing $t$ to 60 or 120 s results in two or three peaks with FWHM less than $1 \mathrm{meV}$. The energies of these peaks do not vary from point to point on the samples although there are changes in the relative intensities which are due to flux variations across the wafer during growth $(2,7)$. The separation of the peaks corresponds to well widths of 21,22 and $23 \mathrm{ML}$ by comparison with the transitions predicted by a finite square well model. The evolution of these PLE spectra is consistent with the smoothing of the interfaces which are thought to consist of large (on the scale of the exciton diameter) lateral islands with occasional ML

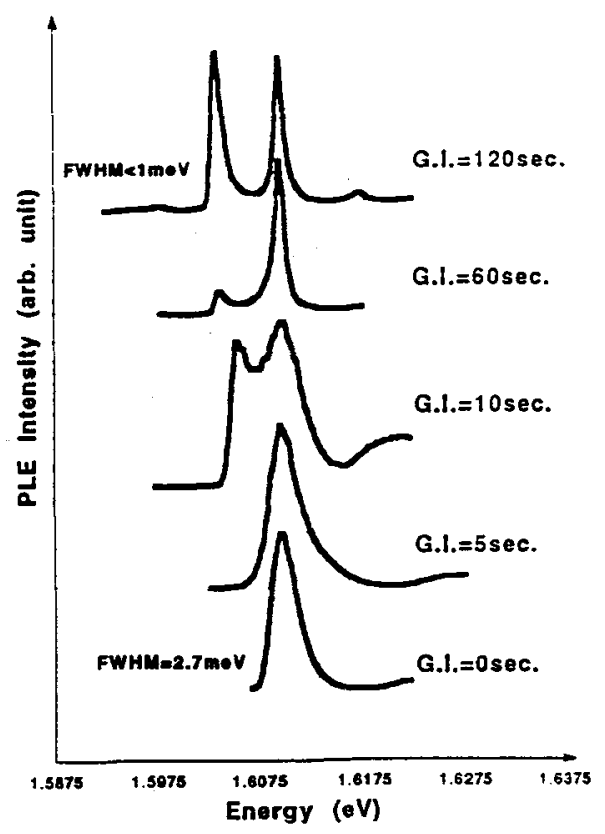
steps (8). 
These results indicate that at least for the structures studied here a GI period of 60 s is required in order to obtain smooth interfaces.

PL spectra at $10 \mathrm{~K}$ for the same samples are shown plotted on a semilogarithmic scale in figure 2, (energies are shifted for clarity). The purpose of this figure is twofold. First, it demonstrates the increased incorporation of carbon impurities with increasing GI period which leads to the weak emission occurring on the low energy side of the spectra. Two peaks are observed corresponding to $\mathrm{C}_{\mathrm{As}}$ impurities at the interface or the centre of the well (9). Secondly, the stokes shift decreases from about $2 \mathrm{meV}$ at $t=0$ to a negligibly small value at $t=60$ or 120 s which is taken as further evidence of interface smoothing. The integrated emission of the samples at low temperatures of the same order and this is reflected in the PL decay measurements where the measured excitonic lifetimes are of the order of $300 \mathrm{ps}$ which is typical of high quality material (10). However, the integrated emission at $66 \mathrm{~K}$ where the $C_{A s}$ free to bound emission is quenched and the excitonic radiative lifetime is expected to be longer (10), shows a dramatic decrease with increasing $t$ as shown in Table $I$, indicating that nonradiative centres dominate the recombination. This is confirmed by PL decay measurements which show a reduction in the measured lifetime from 1.3ns to 300ps as shown in Table 1 .

Recent publications have demonstrated a modest increase in the $77 \mathrm{~K}$ emission of InGaAs/(Al, Ga)As QW by the use of atomic hydrogen which is thought to passivate interface defects or deep non-radiative centres $(11,12)$. Figure

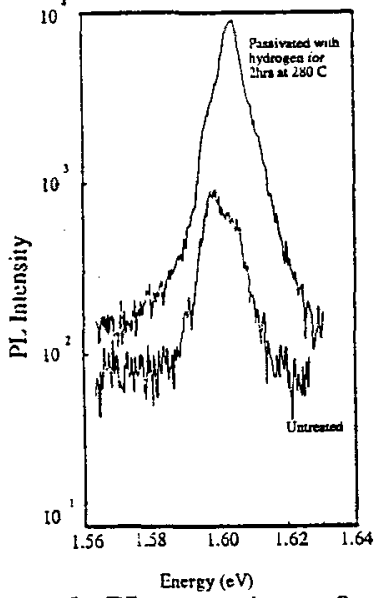

Figure $3: \mathrm{PL}$ spectra from an untreated and an $\mathrm{H}-$ passivated sample with
3 shows the 10K PL spectra obtained from the sample with GI $t=120$ s before and after anneal in a $\mathrm{H}$-plasma for $2 \mathrm{~h}$ at $280^{\circ} \mathrm{C}$. At $10 \mathrm{~K}$ the integrated emission intensity is increased by a factor of 2 . However, at $66 \mathrm{~K}$ the relative strength of the emission has increased by nearly an order of magnitude and is comparable with the nonGI sample. A comparison of the low temperature spectra shows that the $\mathrm{H}-$ anneal does not degrade the interfaces and we conclude that the $H$ has passivated the non-radiative centres but does not encourage interdiffusion at the interface. This convlusion is born out by the PL decay time measurements which are shown in table I. A control experiment was also performed where the samples were annealed without the H-plasma. No differences were found in the PL spectra of any of the samples. $t=120 \mathrm{~s}$. 
Table I:

\begin{tabular}{|c|c|c|c|}
\hline $\begin{array}{l}\text { Sample GI } \\
\text { Period (secs) }\end{array}$ & $\begin{array}{l}\text { Hydrogen } \\
\text { Passivation } \\
\text { Time (hours) }\end{array}$ & $\begin{array}{l}\text { 66K External } \\
\text { Luminescence } \\
\text { Efficiency (au) }\end{array}$ & $\begin{array}{l}\text { 66K PL Decay } \\
\text { Time (ns) }\end{array}$ \\
\hline 0 & 0 & 1 & 1.3 \\
\hline 5 & 0 & 1.1 & 1.3 \\
\hline 10 & 0 & 0.7 & 0.6 \\
\hline 60 & 0 & 0.06 & 0.3 \\
\hline 120 & 0 & 0.08 & 0.3 \\
\hline 120 & 2 & 0.6 & 0.9 \\
\hline
\end{tabular}

Clearly the PL efficiency and decay time data presented in Table I qualitatively support our conclusions on the effects of GI and hydrogen passivation however the two types of measurement do not agree quantitatively if we assume that the exciton radiative lifetime is constant for the different samples. It is possible that the this effect is due to the dependence of the radiative lifetime on the density of interface defects as proposed by Citrin (13). This phenomena is currently under investigation.

3. CONCLUSIONS

GI leads to smoother heterointerfaces if the GI period is 60 s or more but there is a decrease in the luminescence efficiency which can be attributed to the incorporation of non-radiative centres. Carbon impurities are also incorporated during GI. Anneals in atomic $\mathrm{H}$ increase the $Q W$ luminescence presumably through the passivation of the nonradiative centres but do not make the interfaces rough.

Work is now under way to study both the thermal stability of the passivated species and the transport properties of the H-passivated GI samples.

4. REFERENCES

(i) Sakaki H, Noda T, Hirakawa K, Tanaka M and Matsusue, Appl.Phys.Lett. 51 (1987) 1934

(2) Yoshinaga A, Mookherjee P B, Murray R, Neave J H and Joyce B A, J.Cryst. Growth 127 (1993) 788

(3) Bimberg D, Mars D, Miller $J$ N, Bauer $R$ and oertel D, J.Vac.Sci.Technol. B4 (1986) 1014

(4) Dawson $P$ and Woodbridge K, Appl.Phys.Lett. 45 (1984) 1227

(5) Nandhra P S, Newman R C, Murray R, Pajot B, Chevallier J, Beall R B and Harris $\mathrm{J} J$,

Semicond.Sci.Technol. 3 (1988) 356

(6) Nabity J C, Stavola M, Lopata J, Dautremont-Smith W C, Tu C W and Pearton $S \mathrm{~J}$,

Appl.Phys. Lett. 50 (1987) 921

(7) Gammon D, Shanabrook B V and Katzer D S, Appl.Phys.Lett. 57 (1990) 2710

(8) Kopf R F, Schubert E F, Harris T D and Becker R S, App1.Phys.Lett.

58 (1991) 631

(9) Bastard G, Phys.Rev. B24 (1981) 4714

(10) Feldman J, Peter G, Göbel E O, Dawson P, Moore K, Foxon C T and Elliot R J,Phys.Rev.Lett. 59

(1987) 2333

(11) Lord S, Roos G, Pezeshki B, Harris and Johnson N M, Appl.Phys.Lett. $60(1992) 2276$

(12) Gal M, Tavendale A, Johnson M J and Usher B F, J.Appl.Phys. 66 (1989) 968

(13) Citrin D S, Solid State Comms. 84 (1992) 281 